\title{
Cenplesto
}

\section{A ressignificação da praça pública e do sebo como lugares de mediação cultural}

\author{
Hélio Márcio Pajeú \\ Doutor; Universidade Federal de Pernambuco, Recife, PE, Brasil; \\ heliopajeu@gmail.com.br \\ Ana Carolina Correia Sobral \\ Bacharela; Universidade Federal de Pernambuco, Recife, PE, Brasil; \\ carolina.literacia@gmail.com
}

\begin{abstract}
Resumo: O trabalho apresenta parte de uma pesquisa etnometodológica, iniciada em julho de 2013, acerca da Praça do Sebo, localizada no centro da cidade do Recife, que desde 1981 abriga alfarrabistas, distribuídos em 19 boxes, tornando-se um espaço único na cidade para venda de livros antigos, novos, raros e usados. Procurou-se entender o conceito de praça pública e sua importância para a configuração da cidadania, a fim de estabelecer uma possibilidade de ressignificação dos espaços urbanos a partir da mediação cultural. Situa historicamente a relação dos sebos e livreiros com o espaço na construção de memórias coletivas e aborda a problemática do bibliotecário como produtor e mediador de cultura. Apresenta as práticas do projeto \#MovimentePraçaDoSebo e alguns resultados alcançados, relatando as experiências e ações culturais já realizadas ao longo de seu desenvolvimento.
\end{abstract}

Palavras-chave: Mediação cultural. Leitura. Espaços públicos. Praça do sebo. Recife.

\section{Introdução}

É já lugar comum a afirmação de que Recife é um centro cultural a céu aberto. Recife de história e cultura. Recife de rios, ilhas, pontes e manguezais. Recife eternizado pelos poetas. Afirmações que significam (ou deveriam significar) um forte sentimento de conservação pelos espaços públicos - por parte da população e dos governantes; uma sólida consciência de preservação do patrimônio histórico; e uma expressiva preocupação com a memória. No cotidiano da cidade, contemplamos uma realidade completamente oposta àquela exaltada por poetas e músicos em odes ao Recife, mas, incansavelmente, mantemo-nos com uma imagem ainda sonhada por muitos cidadãos, posto que a 


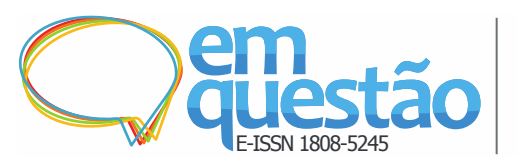

A ressignificação da praça pública e do sebo como lugares de mediação cultural Hélio Márcio Pajeú e Ana Carolina Correia Sobral

cidade esteja abraçada por bibliotecas, museus, arquivos, mercados públicos, parques, praças etc., ambientes essencialmente rodeados de cultura, história e informação. Ambientes nos quais a atuação do bibliotecário se justifica a partir do momento em que há necessidade de gestão, mediação e produção de conhecimento.

O chamado "centro cultural a céu aberto" não se configura como tal sozinho. Dito isso, pode-se confirmar que a cidade do Recife é marcada intensamente pelas artes e multiculturalidade, com um incontestável potencial turístico, cheia de ricas tradições, rodeada de equipamentos sociais, porém, pouco - ou de forma defasada - explorada e administrada.

As praças estão inseridas num contexto em que a paisagem deve ser, primordialmente, bem valorizada e seus espaços devem ser bem estruturados e planejados. Uma praça pública tem, por excelência, o sentido do encontro. É um lugar intencional da permanência, dos acontecimentos, das práticas sociais, das manifestações da vida urbana e comunitária. É um lugar privilegiado e tradicional de trocas, um ponto de convergência harmônica na cidade. A praça perde esse sentido quando problemas sociais, como a insegurança, se sobrepõem e inibem a população de frequentá-la, quando o abandono desmancha a proposta de paisagem inicial, quando a ausência de um modelo de gestão faz com que não se cumpra sua verdadeira função social.

É o caso da Praça do Sebo, no Recife, construída em 1981, com um objetivo específico: abrigar livreiros em 19 boxes (quiosques). Nos anos 80, quem gostava de literatura e de comprar livros a baixo custo, sabia bem onde encontrá-los. Milhares de livros, discos, revistas, jornais, almanaques, gibis, folhetos, cordéis, postais - de segunda mão e novos, em variadas línguas, para todos os paladares literários, eram (e são) encontrados nessa praça, localizada no coração do Recife no bairro de Santo Antônio. Recife foi pioneira nessa experiência de criação de um espaço cultural que atende às demandas literárias, congregando todos os sebistas da cidade (os da época que se concentravam na Rua Infante D. Henrique, vendendo livros em tábuas) num só lugar.

A Praça do Sebo é um exemplo vivo de equipamento cultural: une história, arte, informação e cultura. Porém, foi esquecida ao longo dos anos. Foi 


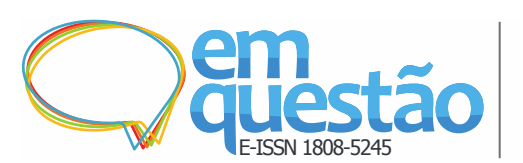

A ressignificação da praça pública e do sebo como lugares de mediação cultural Hélio Márcio Pajeú e Ana Carolina Correia Sobral

nesse sentido de resgate e requalificação que surgiu o projeto \#MovimentePraçaDoSebo, que tem por objetivos: divulgar a Praça do Sebo; valorizar a história e importância dos sebos; destacar a importância da promoção de atividades culturais para movimentar a praça e incentivar o gosto pela leitura, integrando-a com ações culturais. Nesse projeto, primeiramente, buscou-se entender o bibliotecário como mediador cultural, em seu sentido mais intrínseco e, por conseguinte, aplicar a expertise da profissão de forma a impactar positivamente o espaço público da praça. $\mathrm{O}$ interesse pelo tema e consequente início da atuação ocorreu em julho de 2013 e arquitetou vivências; experiências e conhecimentos adquiridos sobre praças, sebos e ações culturais, que se unem para caminhar esforçadamente atrás de um objetivo comum: promoção da leitura em equipamentos sociais nos espaços públicos.

Há uma concordância de que a Biblioteconomia e a Ciência da Informação são responsáveis, em sua essência, por promover a competência informacional, tornando o bibliotecário um agente de transformação social e de impacto na geração de conhecimentos (SARACEVIC, 1996). Como Wersig e Nevelling (1975) apontaram, a CI desenvolveu-se historicamente porque os problemas informacionais modificaram sua relevância para a sociedade ou, em suas palavras, porque tem o dever “[...] atualmente, de transmitir o conhecimento para aqueles que dele necessitam é uma responsabilidade social, e essa responsabilidade social parece ser o verdadeiro fundamento da CI." (WERSIG; NEVELLING, 1975, p. 138). Destarte, compreender que profissional do campo informativo exerce uma função que naturalmente causa impacto para as pessoas e para a cidade foi essencial para o desenvolvimento da proposta, sobretudo na ótica da mediação cultural.

Portanto, o principal objetivo deste trabalho é discutir a Praça do Sebo no seu papel de equipamento de cultura, sob a ótica da mediação cultural promovida pelo bibliotecário, para vislumbrar as potencialidades de um espaço que se mantém há 35 anos com uma proposta única na cidade, quiçá no Brasil: venda, troca e compra de livros novos, usados e raros. Esse objetivo nasceu de alguns questionamentos: como explorar a capacidade total de uma praça que tanto se assemelha a livrarias e bibliotecas? Se em livrarias e bibliotecas é 


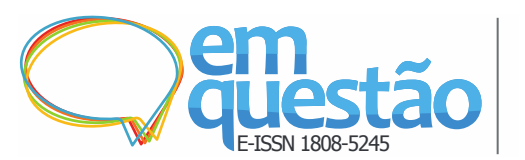

A ressignificação da praça pública e do sebo como lugares de mediação cultural Hélio Márcio Pajeú e Ana Carolina Correia Sobral

frequente a prática de atividades literárias, lúdicas e artísticas, por que não ser comum acontecer o mesmo em praças públicas? O que falta para transformá-la efetivamente num ambiente conhecido e reconhecido pela sua verdadeira função?

Nesse sentido, refletiremos o bibliotecário como mediador de produtos culturais, visto que é seu dever colocar-se no mundo como um profissional habilidoso em coletar informações e heranças culturais e promover sua mediação entre os sujeitos. Muller (1984, p. 20) ao citar Butler (1993) assevera que "o conhecimento só tem significado social quando é adquirido por alguém que o injete de volta na corrente vital da vida da sociedade". Isso, torna-o um profissional e sujeito responsável, que tem a obrigação moral de participar efetivamente dos processos que promovam a mediação e apropriação da cultura, uma vez que isso ocorre no:

[...] reconhecimento real da sua própria participação no existir como evento singular, coisa que não pode ser adequadamente expressa em termos teóricos, mas somente descrita e vivenciada com a participação; aqui está a origem do ato e de todas as categorias do dever concreto, singular e irrevogável. (BAKHTIN, 2010, p. 96).

Isto é, um sujeito que responde e se engaja às demandas sociais a partir da constituição de atos materializados na concretude dos eventos da vida.

Nosso caminho metodológico se deu pela pesquisa-ação, visto os anos de investigação e atuação no espaço e a necessidade de esclarecer e vivenciar conceitos e entendimentos que perpassam o objeto de estudo. Segundo Elliot, a pesquisa-ação é um processo que vai “[...] aclarar e diagnosticar uma situação ou problema que se quer melhorar ou resolver; formular estratégias de ação; desenvolver essas estratégias e avaliar sua eficiência; ampliar a compreensão da nova situação." (ELLIOT, 1997, p. 17). Durante o processo, procurou-se extrair as evidências mais pontuais que permitissem compreender a situação pelo olhar dos próprios atores sociais.

O vivenciar etnometodológico também permitiu que a experiência de interação entre sujeitos numa dada esfera cultural, na Praça do Sebo, fosse singularizada, produzindo dados de conhecimento a partir da observação e da coparticipação em eventos, manifestações e diálogos. Nesse tipo de inserção no 
universo da vida, o pesquisador não erige uma relação abstrata, mas uma interação intensa numa dada cronotopia que forma vicissitudes entre a aproximação e a separação em relação a sua própria região de pesquisa. Essa posição de deslocamento é complexa porque se configura como o lugar de descoberta do outro, posto que seu princípio seja compreender o diferente e, por esse motivo, tem a alteridade como fundamento. Nesse caminhar, segundo Magnani (2002, p. 18):

[...] o que se propõe é um olhar de perto e de dentro, mas a partir dos arranjos dos próprios atores sociais, ou seja, das formas por meio das quais eles se avêm para transitar pela cidade, usufruir seus serviços, utilizar seus equipamentos, estabelecer encontros e trocas nas mais diferentes esferas.

Esse trabalho procura, assim, compreender a cultura e seus objetos culturais não expressos demasiadamente por vias teóricas, mas sim por uma inclusão no contexto em que se dão os tons valorativos dos grupos sociais organizados e suas ações por meio da interação dialógica e a importância dessa ação desenvolvida pelos bibliotecários. De modo geral, esperamos que o assunto desperte interesse para o desenvolvimento de estudos futuros acerca da ressignificação de espaços públicos pela dialogia da mediação cultural, sobre o comércio livreiro e como o mesmo pode incentivar o gosto pela leitura; fonte para novas inquietações sobre o significado social e positivo que as praças podem exercer e reflexão sobre os pontos desconectantes da função que deveriam cumprir; bem como para novas inspirações em que o bibliotecário possa atuar e se posicionar como mediador da cultura e da memória.

\section{Função social das praças e sua ressignificação}

A praça, sendo aberta e livre, cria condições para que nela se produzam realizações e relações sociais que possibilitam e dão sentido à vida urbana, que resguarda historicamente em sua essência a ideia de convivência humana (ANDRADE, 2011). Sua função primordial é a de aproximar e reunir as pessoas, seja por motivo cultural, econômico (comércio), político ou social (ROBBA; MACEDO, 2002). Ela configura um espaço da memória histórica que 
forneceu tanto a moldura quanto o fundo, para discursos políticos e culturais sobre a cidade como local de identidade, tradição, saber, autenticidade, continuidade e estabilidade (DE ANGELIS, 2005).

Historicamente, podemos citar a civilização grega, conhecida por ser o berço da democracia, política, filosofia e conhecimento, como referência e precursora para entender a contextualização de praças públicas. Na Idade Antiga, a função das praças era rica em significado, não se limitando ao cruzamento de vias públicas ou estacionamento, como vemos muitas no contexto atual. No Brasil, a praça foi considerada como o espaço urbano mais importante, já nas primeiras cidades coloniais. Nela, encontravam-se todos os edifícios administrativos e cívicos: a casa da redenção, a câmara, a cadeia, o pelourinho e, em muitos casos, comportam o poder municipal, o palácio do governador e a igreja (SOUSA; OLIVEIRA, 2010).

Pode-se exaltar a função secular das praças, o seu simbolismo e sua importância na configuração e dinamicidade de uma cidade, posto que esse espaço potencializa a identidade urbana e a torna parte fundamental do progresso, indissociável da inclusão social, dos direitos básicos de um cidadão. São organismos vivos que necessitam estar em congruência com o desenvolvimento das cidades, evitando que se deteriorem por conta do passar dos anos ou, simplesmente, pela falta de sensibilidade, atenção e manutenção do poder público (CALDEIRA, 2007).

Mikhail Bakhtin considera a praça um equipamento riquíssimo para o estudo da condição humana e das práticas sociais, exatamente por ela ser composta pelo povo, ser “[...] um todo popular, organizado à sua maneira, à maneira popular, exterior e contrária a todas as formas existentes de estrutura coercitiva social, econômica e política e essa organização é antes de tudo, profundamente concreta e sensível." (BAKHTIN, 2008, p. 222). Por esse motivo, o filósofo russo dedicou parte da sua obra a discussão do lugar social das práticas cotidianas na praça pública, nas feiras, nos ambientes intimamente ligados ao povo, que revela os lugares que refletem e dos quais emergem os indícios que identificam as ideologias circulantes na sociedade. Para ele, tais aspectos contribuem para se "criar uma atmosfera especial da praça pública com 
o seu jogo livre e alegre, no qual o superior e o inferior, o sagrado e o profano adquirem direitos iguais e são incorporados em coro na ronda verbal" (BAKHTIN, 2008, p. 138).

Os espaços públicos, sobretudo as praças, tem despertado o interesse de arquitetos, urbanistas, cientistas políticos e sociais, historiadores e, inclusive, de bibliotecários, como objetos de pesquisa para se refletir o sentido de urbanidade atual: uma preocupação em recuperar, reestruturar, reativar e ressignificar espaços públicos, concretizando anseios por manter e, em alguns casos, requalificar espaços que estão perdendo seus significados sociais, dando lugar a construções capitalistas (shoppings e estacionamentos) e esquecendo da sociabilidade, integração e convívio entre os sujeitos (LOUZADA, 2011).

Segundo France (1988), a imagem da cidade forma-se a partir da relação dos habitantes com seus espaços públicos. É consensual que, ao falar de praças, não se pode perder de vista a espacialidade e o contexto das cidades. Essa, talvez seja sua maior função social, pois são construídas por e para as pessoas, e só há sentido se houver manifestações e intervenções, que mostrem a dimensão cultural e o impacto positivo que o lugar proporciona.

Nessa direção, ao pensarmos na ressignificação desses espaços, nos referimos à capacidade do ser humano de, a partir da reflexão acerca de um acontecimento, atribuir-lhe significados, ora distintos da primeira significação, ora reafirmando-os (SILVA et al., 2008). A ressignificação é um processo que permite atribuir um sentido inédito ou original à determinada experiência, carregando consequências para a forma como se situa diante da história. Pode-se dizer que é, também, uma habilidade de atribuir um significado positivo, satisfatório, para uma situação incomodativa ou prejudicial, de tal forma que, após ressignificado, seja encarado com uma nova visão de mundo. Trataremos, então, a ressignificação como mudança de visão, de sentido e aplicação de ações transformativas. Ser capaz de ressignificar é encarar a complexidade de uma situação e simplificá-la, ou apresentar soluções.

A praça pública, assim como outros espaços urbanos, pode servir de material para o emprego da proposta de ressignificação, levando a elas a dinamicidade e ativação que precisam para se configurarem como instrumento 


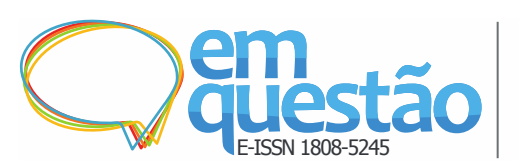

A ressignificação da praça pública e do sebo como lugares de mediação cultural Hélio Márcio Pajeú e Ana Carolina Correia Sobral

de desenvolvimento social - dado que a postura dos governantes no que tange praças públicas, em todo território nacional, é de abandono, e da sociedade para com as praças é de pouco usufruto. Nesse processo de apreensão e produção de sentidos, o bibliotecário, nas suas ações de mediação como ato de significar (PERROTTI; PIERUCCINI, 2014), tem um papel fundamental como intermediário da cultura e da informação.

\section{0 bibliotecário mediador cultural}

Sendo a biblioteca uma das primeiras instituições a lidar com a informação e a desempenhar um papel fundamental para com a preservação da mesma, era evidente uma preocupação maior com os procedimentos técnicos de catalogação, classificação e linguagens que levavam ao acesso e busca dessas informações do que com o usuário que dela necessitava e o leitor. Erroneamente, mas em consonância com a realidade, o bibliotecário adquire uma imagem tecnicista, de um profissional imerso nos livros, unicamente voltado para representar e guardar o conhecimento, esquecendo-se da formação de seus usuários e promoção da leitura.

Com o advento dos meios de comunicação e das novas tecnologias na Sociedade da Informação e do Conhecimento, o bibliotecário precisou se adequar e atualizar-se, entendendo que ele é um gestor de produtos e serviços que deve cumprir uma função social e educacional importante junto à sua comunidade. É apropositado que o profissional identifique as necessidades sociais do seu entorno e conheça profundamente seu usuário, permitindo mediações que contribuam para o enriquecimento pessoal e comunitário.

O bibliotecário se redefine e quebra essa tradição histórica, tecnicista e custodialista no momento em que adota um posicionamento de mediador da ação fundamental do nosso século: o ato de informar. Ser mediador da informação inclui instrumentalizar seu usuário e oportunizar caminhos para o conhecimento de modo democrático. O uso das tecnologias e o efeito de ações culturais, para fins educacionais e de sociabilidade, é tão impactante e crucial no progresso coletivo que consegue inserir o indivíduo num novo cenário: ele 
ultrapassa os limites da omissão informacional, do afastamento ou, até mesmo, da recusa em fazer parte dessa realidade e se põe, perfeitamente disposto, como cidadão consciente de seus direitos e deveres e que também é capaz de produzir o novo. Não se pode falar em contemporaneidade, e continuar mantendo-a ausentedo cotidiano dos grupos, o que é refletido no despreparo do sistema educacional e na falta de bibliotecas adequadas - ou seja, em tudo aquilo que é parte integrante do direito à cidadania e, inclusive, de condições básicas de vida.

A atuação do bibliotecário, quando em plena consciência de suas atividades, promove, facilita e instiga não só o consumo, mas a produção de cultura, levando o sujeito à reflexão e autonomia, dentro do que nos ensina Paulo Freire (1975). Sobre essas ações, Almeida (1987) diz que:

[...] estão ligadas à ideia de transformação, de emancipação a partir da expressão. Diz respeito não apenas a produtos culturais acabados, como também às condições que levam à capacidade criativa, à produção cultural. Relaciona-se por outro lado, ao processo de educação coletiva, no momento em que desenvolve atividades práticas e abre espaço para a troca de informações e a discussão sobre temas de interesse do grupo. (ALMEIDA, 1987, p. 33).

O homem é pertencente e parte do mundo, mas é, também, atuante. O bibliotecário detém a habilidade de construir um ambiente reflexivo e crítico, incitando valores, incentivando debates, fomentando a cultura e a mediação dos seus objetos culturais. De acordo com Abbagnano (1998), e aqui concordamos com ele, o termo cultura abraça dois significados básicos: “[...] significa a formação do homem, sua melhoria e seu refinamento. [...] Indica o produto dessa formação, ou seja, o conjunto dos modos de viver e de pensar cultivados, civilizados, polidos." (ABBAGNANO, 1998, p. 225). Bem como se relaciona a educação "[...] devida às boas artes peculiares do homem, que o distinguem de todos os outros animais. As boas artes eram a poesia, a eloquência, a filosofia etc., as quais se atribuía valor essencial para aquilo que o homem é e deve ser." (ABBAGNANO, 1998, p. 225).

Já a expressão mediação cultural pode ser compreendida como o estimular à curiosidade, o gosto pelo conhecer, pelo experimentar algo que até o momento não se conhece. $O$ intuito não é impor uma cultura, ou uma manifestação artística como a correta, mas sim apresentá-las. A principal meta 


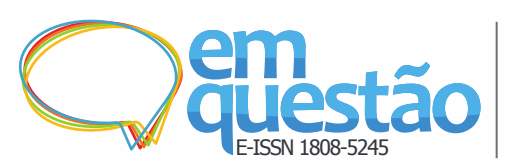

A ressignificação da praça pública e do sebo como lugares de mediação cultural Hélio Márcio Pajeú e Ana Carolina Correia Sobral

da mediação cultural é nutrir o pensar e agir, a reflexão; é constituir identidades pela alteridade, valores, senso crítico, debates políticos, humanitários e sociais e esses processos constituem parcelas da mediação cultural.

Segundo Perrotti e Pieruccini (2014) a mediação é um experimento de combinação em uma ação, destarte, necessita de intermediários e de terceiros. Tem-se, assim:

[...] um termo (mediação) que remete ao campo das relações, das intermediações sociais entre sujeitos. De outro lado, temos o adjetivo 'cultural' que o qualifica, restringe, particulariza, circunscrevendo-o ao domínio semiológico, distinguindo a 'mediação cultural' de outras formas de mediação (política, econômica, social, religiosa, diplomática), com as quais mantém afinidades, mas ao mesmo tempo se diferencia. Em outras palavras, tal como nos demais campos, a mediação cultural é um ato de intermediação por um 'terceiro' visando viabilizar relações e convivência dos sujeitos entre si- o 'viver junto'. (PERROTTI; PIERUCCINI, 2014, p. 8).

Nesse processo de mediação, é pertinente separar os conceitos de ação cultural e animação cultural para um maior entendimento. Coelho Neto (1989; 2001), diz que animação é o simples ato de oferecer shows, espetáculos, sem fundamento ou perspectiva de reflexão sobre aquilo. Em lado oposto está a ação, que lança os alicerces para uma construção reflexiva coletiva e propõe interação de todos, sem um final estabelecido, afinal, vai prevalecer a criatividade de cada um, os quais são protagonistas de suas criações. Entre as principais características do mediador cultural, José Filho (2009), enumerou algumas, e é conveniente observamos, que caracterizam as atividades desenvolvidas na trajetória da Praça do Sebo:

[...] seu trabalho deve impulsionar as potencialidades econômicas, sociais e turísticas na cidade; Deve promover o entendimento cultural entre os diversos segmentos sociais da comunidade levando-os à compreensão dos processos; Deve ser um articulador dos processos culturais junto ao poder público; Ser um gestor com capacidade inventiva e formadora de mentes críticas; Ter sensibilidade voltada para o sociocultural; Entender que os homens não são seres vazios e por isso é preciso enchê-los de conteúdos; Não possuir uma mente mecanizada, mas sim humana. (JOSÉ FILHO, 2009, p. 24).

Nesse sentido, o bibliotecário é, por formação, um mediador cultural, e assim sendo, precisa conhecer o momento histórico dos indivíduos com os quais 
ele vai interagir, realizando ações possíveis hoje para viabilizar o impossível de amanhã, e juntamente com eles ir descobrindo mecanismos para uma consciência de mediação crítica, fazer com que as ações desenvolvidas se tornem também revolução cultural (JOSÉ FILHO, 2009). Nesse sentido:

[...] a mediação cultural não se constitui meramente como jogo de saberes especiais ou especializados em vista de um fim determinado que lhe é exterior. É ato de afirmação ética, destinado a transcender o âmbito dos interesses mundanos (PERROTTI; PIERUCCINI (2014, p. 10).

\section{Os alfarrábios no coração do Recife}

Existem algumas especulações para o surgimento da expressão "sebo". A mais provável tem completa ligação com a história do papel. Quando ainda não havia energia elétrica, costumava-se ler à luz de velas. As velas, na época, eram feitas de gordura animal (sebo) e sujavam as páginas e livros na medida em que derretiam, deixando-os engordurados, ensebados ou sebentos. O que, então, fez com que se caracterizasse, posteriormente, como "sebo" aquele livro usado, surrado, velho e, consequentemente, o lugar que os vende. Os mercadores que comercializavam livros e documentos importantes, por volta do século XVI na Europa, eram conhecidos como alfarrabistas - termo usado até hoje, principalmente em Portugal e que deriva de "alfarrábio", livro antigo ou raro. Nessa época surgiram os primeiros sebos (o espaço propriamente dito das vendas desses livros). Atividade ainda plenamente comum e respeitável nos países europeus em dias atuais. Há quem diga, também, que "alfarrábio" deriva de Al-Farabi, um filósofo muçulmano, nascido no Turquestão, que viveu em Bagdá e que, por seus conhecimentos e reputação de grande leitor, emprestou seu nome aos livros e documentos antigos, velhos, valiosos, raros ou comuns (LIMA, 2009).

O profissional dos sebos já foi chamado também de caga-sebista, sendo mais comum, hoje, apenas "sebista". Alguns sebistas condenam o nome "sebo" por acharem difamatório e que remete seu trabalho à imagem do sujo ou malcuidado. Aos poucos, os sebos têm buscado se modernizar, com ambientes climatizados, ampliando as instalações - como um café, e até concebendo uma 


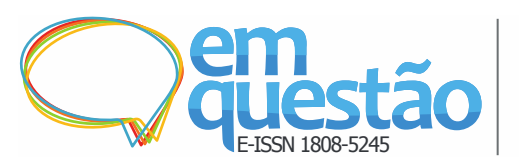

A ressignificação da praça pública e do sebo como lugares de mediação cultural Hélio Márcio Pajeú e Ana Carolina Correia Sobral

catalogação intuitiva para melhor organizar o acervo. Apesar de muitas nomenclaturas, todas querem designar uma livraria singular, na qual se vendem, trocam e compram livros. Isto é, todo sebo pode ser considerado uma livraria, porém, nem toda livraria pode ser um sebo. Sendo assim, Delgado afiança que:

[...] a importância dos sebos está no fato de serem espaços que, além de possibilitarem um preço mais acessível para o livro, permitem que se encontrem ali edições esgotadas, já fora de circulação do mercado, bem como livros raros e coleções valiosas. Os sebos permitem, ainda, outras formas de negociação que as livrarias de livros novos não utilizam, como troca e compra de livros. (DELGADO, 1999, p. 53).

Preços baixos, livros esgotados ou que saíram de circulação, edições não mais impressas, livros raros, autografados, primeiras edições; são traços peculiares dos livros possíveis de serem encontrados em sebos. Verifica-se que apontamentos como memória, preservação, história, cultura, educação e conhecimento permeiam naturalmente a realidade alfarrabista. Professores, estudantes, pesquisadores, curiosos, colecionadores, historiadores e bibliófilos formam o público frequentador (e fiel) de tais espaços. Os sebos atravessam o imaginário do povo, com a idealização de lugares abarrotados de livros, empoeirados, talvez até um pouco escuros, em que o sujeito se perde no tempo e nas estantes garimpando e remexendo em tudo (MANSUR, 2007).

Aos sebos também compete o incentivo à leitura. A troca de livros, a consignação e o baixo preço já favorecem o acesso e dão alternativas ao leitor, que não precisa submeter-se aos altos preços das grandes livrarias. Esse mercado promove, seguramente, a leitura, independente do eixo temático que trabalhe o sebista, ele sempre está indicando, sugerindo, compartilhando experiências, conversando com seu cliente, isto é, também assumindo a identidade de mediador cultural. Isso é notável na personalidade dos livreiros, especialmente falando da Praça do Sebo - Centro da Cidade do Recife - nosso objeto de estudo e referência para todas as reflexões aqui expostas. Eles demonstram o amor pela atividade em cada referência e orientação aos clientes, indo além da simples venda. Coincidência, ou não, esse papel se confunde com o do bibliotecário. Nos dois casos, está sendo viabilizado um caminho para o leitor chegar até os livros. 


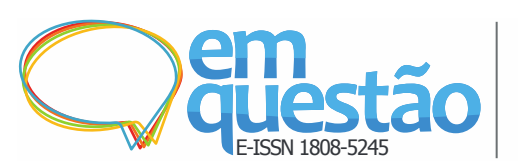

A ressignificação da praça pública e do sebo como lugares de mediação cultural Hélio Márcio Pajeú e Ana Carolina Correia Sobral

Em conformidade com Amorim (2013), pode-se afirmar que:

[...] assim como as bibliotecas, os sebos otimizam o acesso ao conhecimento, claro que de formas diferentes, apesar de que o usuário de biblioteca deve ser visto da mesma forma que o cliente é visto pelo comércio, isto é, como aquele que merece o melhor, que tem sempre razão, que deve ser bem tratado e que merece atenção. Dessa forma, quando falamos em acesso, é inevitável não falar do bibliotecário. [...] O acesso é para o bibliotecário o que a venda de livros é para o sebista. Ambos propiciam o acesso ao conhecimento e, consequentemente, a geração de novos conhecimentos. (AMORIM, 2013, p. 12).

O sebista com toda sua tradição das ruas, das relações sociais, da oralidade, realiza uma tarefa importantíssima de formar leitores e dar acesso à informação. Além disso, os sebos também contribuem para conhecermos melhor a tradição popular, já que esses profissionais convivem diariamente com a dinâmica das cidades, se comportando como mercados e entendendo das relações pessoais. São verdadeiros contadores de histórias, que, talvez, sem se dar conta, colaboram de maneira significativa para o desenvolvimento intelectual, instruindo os frequentadores e enriquecendo a própria cultura local (CAVAGLIERI, STEINDEL 2009). O nosso objeto de estudo, a Praça do Sebo, já foi batizada de Universidade do Povo ou Universidade Popular do Recife, como descreve o ex-livreiro da PS e mestre em literatura, Pedro Américo Farias ${ }^{1}$ :

\footnotetext{
Ver de perto cada livreiro, suas estantes cheias de brochuras e variados impressos. Reler o país, a história, a vida; conversar um bocado de besteira; ouvir ótimas histórias com $\mathrm{H}$ e sem $\mathrm{H}$; comprar, trocar, reservar livros, pechinchar nos preços, ser ou não ser xingado de pirangueiro. Agora, o melhor de tudo é encontrar os muitos mestres e orientadores de teses nunca escritas, mas impressas nas próprias cabeças - os chamados Sábios do Povo; os colecionadores de fotos, revistas, postais, edições príncipes, quadrinhos, discos de Jakson do Pandeiro, Beatles ou Luiz Gonzaga; os amigos que trazem consigo a amizade e o prazer da leitura. (FARIAS, 2015, p. 1).
}

Os sebos transformam a memória inacessível em acessível ao permitirem o resgate de obras perdidas, pertencentes a um período longínquo, preservando o passado e permitindo a sua recuperação (AMORIM, 2013). O livro está mais vivo do que nunca dentro dos sebos e aberto a todos. O percurso trilhado pelo livro usado é cheio de peculiaridades e dá uma noção de raro, exclusivo, único e singular. Os livros que chegam às mãos dos vendedores (sejam por doações, 


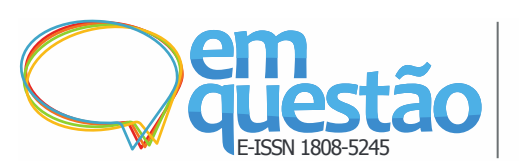

A ressignificação da praça pública e do sebo como lugares de mediação cultural Hélio Márcio Pajeú e Ana Carolina Correia Sobral

compras ou trocas) são repletos de significados. Contracapa, folha de rosto, margens do livro, por vezes chegam aos sebos contendo anotações, dedicatórias, autógrafos e marcas que refletem pensamentos, ideologias e opiniões feitas por alguém que vai transferir sua história para a vida de outra pessoa, no momento da aquisição desta.

O ofício do sebista, do bibliotecário, dos editores, entre outros profissionais do livro é perdurar o conhecimento. Fica evidente que a atividade de um livreiro antiquário vai além do trivial comércio, pois existe responsabilidade com os leitores, a delicadeza com a história do livro, a preocupação com a leitura e um atento cortês com a difusão da informação. Os sebos estão a nossa espera, para aventuras e pesquisas, sempre com um livro para cada leitor, e no Recife eles têm um lugar singular: a Praça do Sebo.

Endereçada como Rua da Roda, s/n, no bairro de Santo Antônio, a Praça do Sebo, tal como um esconderijo secreto, pode passar despercebida pela maioria das pessoas que circulam nas proximidades, irrefletidos (já que inexistem placas e sinalizações) que, entre alguns prédios, se encontra uma paisagem bucólica e uma calmaria, bem no centro da cidade. Quem a conhece sabe que um passo a mais em determinada rua o levará à Praça, tornando essa descoberta como um trufo de conhecimento na manga de quem lê.

Na década de 1920, os primeiros sebos surgiam na cidade do Recife. Tudo ainda de forma muito rudimentar, mas conquistando, em demasia, seguidores, amadores e novos livreiros. Em 1980, a memória livresca continuava percorrendo a cidade, através dos antiquários que, a essa altura, já eram símbolos de cultura e história para o povo. Eles perpetuavam a relação leitor-livro, baseada em respeito, simpatia e gratidão pelos ensinamentos de outrora. Aliás, deparar-se com esses vívidos protetores da cultura popular era ter a certeza de apreender sempre algum novo conhecimento. O comércio ambulante de livros tinha se espalhado, tomava conta de ruas, calçadas e esquinas. Cada sebista vendia à sua maneira. Era grande a concentração, principalmente, em frente ao Banco Safra, na Rua do Sol ou na Rua Infante D. Henrique, no bairro Santo Antônio (ALBERTIM, 2012). 
A história do surgimento da Praça do Sebo é transpassada por pessoas e suas respectivas conexões com o livro, sendo impossível desassociar a criação (e invenção) do espaço dessas figuras representativas. Aqui, trataremos de três em especial que, transversalmente a suas trajetórias, contam-nos a origem da Praça do Sebo: Liêdo, Melqui e Pedro. Contudo, até os dias atuais, cada livreiro é um personagem que vai tecendo, fortalecendo e mantendo a narrativa em sequência.

Hoje, 19 boxes integram o espaço divididos entre os seguintes livreiros: 1, 2 e 3 - Marcelo; 4 - Adriana; 5 - Iraci; 6 - Heitor; 7 - Jacques; 8 e 9 Leonilda; 10, 11 e 12 - Geandra; 13 - Cátia; 14 e 15 - Augusto (único que permanece desde a fundação); 16 - Francisco; 17 - Fernanda; 18 - Tatiana; 19 Carlos.

Em 1981, o prefeito da cidade do Recife, Gustavo Krause, mostrou-se sensível à causa dos sebistas e, contando com 18 sebistas (sob a orientação de Liêdo Maranhão) que exerciam seus ofícios pelas ruas da cidade, criou um reduto para os amantes da leitura e para acomodar os vendedores, tornando Recife uma das raras cidades a concentrar um espaço dedicado aos sebos e para o "lazer e cultura da população", como reflete a placa de inauguração mantida até hoje (FREITAS, 2014).

A primeira década da Praça cumpriu o acordo inicial. Com uma sala para administração e dois banheiros (um público, outro para os funcionários), funcionou de forma admirável. Em meados de 1990, os problemas começavam a sufocar os sebistas e frequentadores. Em 1994, um gradil foi preciso ser colocado para separar os bares que começavam a tomar conta da Rua da Roda e a invadir a Praça, porém, a poluição sonora continuou sendo um problema. A sala de administração se transformou em depósito. Os banheiros se resumiram a um, além disso, a falta de limpeza e policiamento (atestando o esquecimento dos órgãos públicos) afastava os compradores e deixava desgostosos os livreiros. Essa situação se estendeu ao longo dos anos, contando apenas com esporádicas e pequenas reformas que só serviam para encobrir grandes e rotativos problemas, sem solucioná-los verdadeiramente (MENEZES, 2006).

O livreiro, pesquisador, colecionador e dentista por formação, Liêdo Maranhão de Souza, é uma das pessoas que compõe essa história desde o início. 


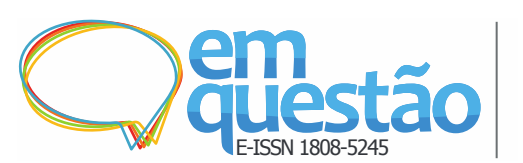

A ressignificação da praça pública e do sebo como lugares de mediação cultural Hélio Márcio Pajeú e Ana Carolina Correia Sobral

Liêdo passou a maior parte da sua vida garimpando publicações antigas em sebos e colhendo depoimentos de populares nas ruas. Foi ele quem sugeriu aos governantes da época transformar um vão entre prédios (que mais servia de ponto de acúmulo de lixo e estacionamento) num local destinado aos livros. Com base em suas muitas pesquisas sobre o imaginário do povo, os mercados, os camelôs e os cordéis, Liêdo acordou a criação e transformação daquela área num ambiente que reunisse os sebistas que passeavam pelas ruas e calçadas. Bem aceita, a proposta foi abraçada e entregue à população em 26 de agosto de 1981. A ideia de Liêdo e demais envolvidos era, além da venda de livros, propor uma praça diferente do habitual, na qual acontecesse uma intensa valorização da cultura pernambucana, através da presença de poetas, cordelistas, repentistas, em constantes eventos culturais, apresentações e lançamentos.

Com referência a esses fatos, Melquisedec Pastor do Nascimento, outra figura emblemática da Praça do Sebo e considerado o maior sebista do Brasil, durante o I Congresso Internacional de Literatura Nordestina, deixou registrado que:

A Praça do Sebo ou corretamente o Mercado de Livros Usados do Recife, foi o movimento mais promissor para a cultura que se fez nesta cidade. Reuniu-se em local digno sebistas precariamente instalados aqui e ali. Eram pequenos comerciantes que, mais ou menos, contribuíam para a continuação desse comércio. Contamos com a iniciativa e o apoio de Liêdo Maranhão, Francisco Balthar Peixoto, Paulo Roberto de Barros e Silva e Edson Wanderley, entre outros, simpáticos a esse comércio cultural. O então prefeito Gustavo Krause determinou a construção. Foi feito um convênio entre os sebistas e a Prefeitura. (NASCIMENTO, 1988, p. 29).

O livreiro, tendo acompanhado de perto toda a expressiva progressão da Praça, tinha opinião formada para explicar o crescente descuidado, que se tornou perceptível a partir dos anos 1990, e assegura que:

[...] os poderes públicos têm coisas mais nobres com que se preocuparem... Como sebistas, alfarrabistas, antiquários ou libervelheiros o que é positivo é dignamente semear livros. Efetivamente, apenas o Dr. Gustavo Krause foi sensível ao comércio de livros usados aqui no Recife, agrupando os sebistas no Mercado de Livros Usados. Os poderes públicos não são sensíveis à problemática da educação, sequer. (NASCIMENTO, 1988, p. 31).

Sobre a atuação cultural e forte contribuição livreira que Melquisedec deixou, Pedro Américo de Farias considera necessário dizer: 


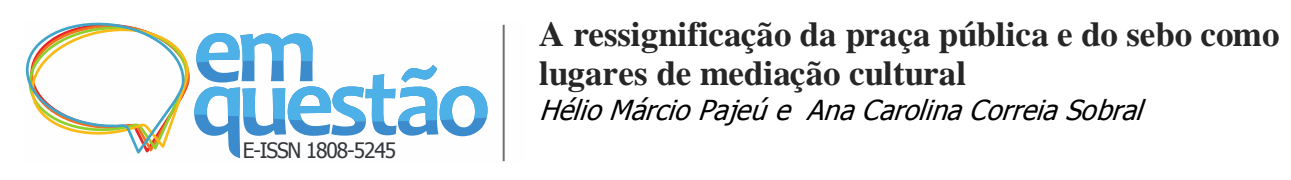

[...] da sua importância como coletor da memória da cidade; da sua honesta política de priorizar os interesses da pesquisa local; do seu respeito aos estudiosos brasileiros, sejam eles da retaguarda ou da vanguarda; da necessidade de Melqui brindar o leitor de Pernambuco, com as suas prometidas memórias; da obrigação institucional dos museus de imagem e som recolherem o acervo deste guardador de rebanho da história intelectual do Brasil. (FARIAS, 2015, p. 2).

Pedro Américo, também figura caricata da Praça, presenciou muitos dos eventos, lançamentos de livros, exposições e recitais de poesia que aconteciam na praça no início dos anos 1980, antes de seus anos de decadência. Grupos folclóricos e culturais como bumba-meu-boi e afoxé também se apresentavam. Aos sábados, era comum o som de berimbau dando ritmo ao jogo de capoeira, até que foi invisibilizada nas marcas do tempo.

\section{O projeto \#MovimentePraçaDoSebo}

Estar na Praça do Sebo, em meio a tantas histórias, causos e contos que retratam como se deu o passar dos anos para nossa cidade, é poder refletir, afinal, questões éticas, estéticas e políticas. As marcas do tempo não estão só nos olhares de saudosismo dos livreiros e nas mornas pedras portuguesas - antes fartas de movimentos, mas também são facilmente visíveis em cada desamparo com os espaços públicos, na disparidade de prioridades em cada governo, no crescente abandono das questões básicas para o centro da cidade. São fatos predominantes para quem viu e viveu toda a riqueza das ruas, para quem se alimenta da vivacidade afora. Praças, mercados, igrejas, polos culturais, nos quais se concentravam a energia cotidiana e onde o desenrolar dos cidadãos acontece, perderam essa característica identitária de grupos sociais que se apropriam e expressam estilos de vida.

E justamente por serem lugares simbólicos de constituição das identidades singulares e coletivas, representativos da vida e da história das cidades, sobretudo os que se encontram nas áreas centrais - o caso da Praça do Sebo -, é que todo desinteresse se qualifica como um explícito caso de negligência com a comunidade, a cultura e a memória. Priorizou-se, aqui, investigar a sociabilidade da Praça do Sebo através de seu histórico e 


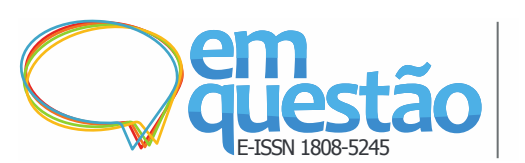

participação popular, a fim de que ela utilize seu passado a favor do desenvolvimento no presente, e tenha uso e aplicabilidade reais dentro de seu contexto.

Diante das reportagens exibidas pela Rede Globo, entre novembro de 2012 e agosto de 2013, documentando o afastamento dos poderes públicos com a Praça do Sebo, sua manutenção e sua utilização, projetou-se uma ideia de resgate espacial, utilizando-se da prática bibliotecária, no sentido de mediar cultura e incentivar a leitura. A ação teria como base aspectos da mediação cultural como a promoção da leitura e ações culturais.

O bibliotecário, ao fazer sua opção para atuar como mediador cultural, deve dar início a um processo de ação cultural emancipatória de conteúdo ideológico (CABRAL, 1999). Como a Praça acabava de passar por uma reforma - fruto da insistência das reportagens - e completaria 32 anos no mês que sucedia, enxergou-se a primeira oportunidade para "testar" a ideia de movimentação cultural. Realizar o "Aniversário da Praça do Sebo", em 30 de agosto de 2013. Inicialmente, a ocasião serviria para marcar o aniversário e a recente reforma. Porém, foi além e tornou-se parte de um movimento de pessoas que acreditam na utilização de espaços públicos como lugares dialógicos de interação social, sujeitos que externam sua sensibilidade artística voluntariamente (escapando da dependência de instâncias superiores), pessoas que visualizam a Praça do Sebo como um bem cultural popular da cidade do Recife. Surgiu então a hashtag que deu nome ao projeto: \#MovimentePraçaDoSebo, com os seguintes ideais: Facilitar o acesso ao livro, à informação; Incentivar o gosto pela leitura; Divulgar a Praça e serviços; Inserir bibliotecas, livrarias e sebos no cotidiano das pessoas; Popularizar a literatura e cultura pernambucana; Envolver a população em atividades de leitura; Desenvolver o senso de preservação e conservação em espaços públicos; Promover o exercício de solidariedade e cidadania.

O designer Pablo Cavalcanti criou uma logomarca para estampar camisas, as quais foram vendidas para custear a vinda de alguns artistas, a decoração e, enfim, toda a realização do evento. Foi a partir da primeira intervenção que ficou bem claro: o histórico recente de abandono e 


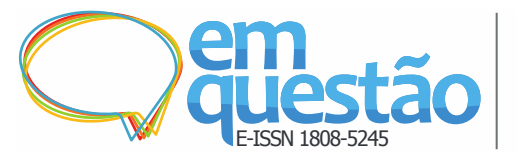

A ressignificação da praça pública e do sebo como lugares de mediação cultural Hélio Márcio Pajeú e Ana Carolina Correia Sobral

esquecimento da Praça, não faria mais parte do presente, sendo assim, o trabalho de divulgação estava dando certo e, por consequência, o estudo e entendimento da utilização e significação de espaços públicos como centros de cultura ganhava corpo.

Figura 1 - Marca do projeto \#MovimentePraçaDoSebo do designer Pablo Cavalcanti

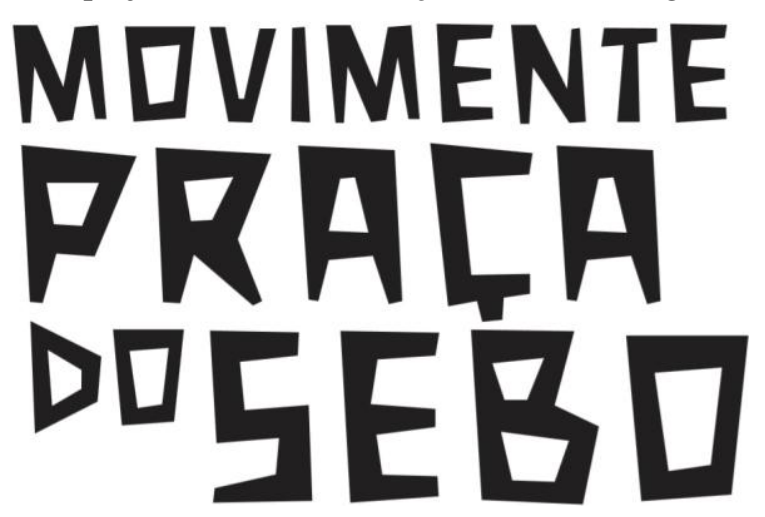

Fonte: Dados da pesquisa.

Em julho de 2013, foi criada a página no Facebook, que ganhou, imediatamente, grande número de apoiadores e entusiastas. Também foi criada uma logomarca para a Praça, em parceria com alunos de Design da Informação, da AESO - Faculdades Integradas Barros Melo, que tomaram a iniciativa de estudá-la sob outra ótica, realizando um minucioso trabalho de confecção da marca, optando por pegar elementos da árvore (barriguda), da sua folha e do alegrete que a envolve.

Figura 2 - Marca da Praça do Sebo elaborado por Alunos de Design da Informação da Faculdades Integradas Barros Melo (AESO)

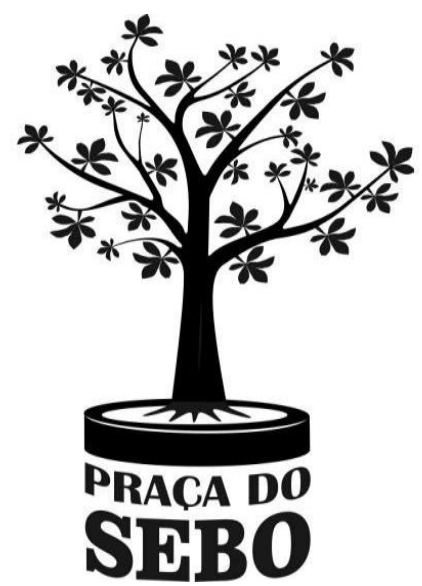

Fonte: Dados da pesquisa. 


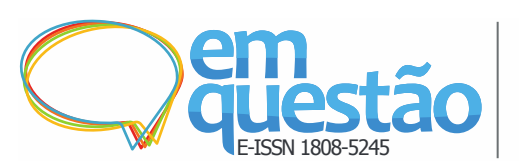

A ressignificação da praça pública e do sebo como lugares de mediação cultural Hélio Márcio Pajeú e Ana Carolina Correia Sobral

A página, utilizada para divulgar os serviços da própria Praça, funcionou como uma ferramenta de marketing social. O público passou a se comunicar e demonstrar interesse, conexões e ideias surgiram, professores se mobilizaram para levar seus alunos em visitas dirigida de escolas públicas e privadas da RMR, artistas independentes vieram de longe apresentar sua arte, músicos, contadores, poetas, escritores, e até mesmo o criador da estátua do poeta Mauro Mota, se fizeram presentes num momento único para a Praça: o renascer! E, assim, foi realizada uma segunda intervenção cultural: o Dia das Crianças na Praça do Sebo.

Na ocasião, a Praça do Sebo reuniu artistas, pais, filhos, educadores e atraiu crianças (de todas as idades), numa agitação que envolveu o mundo fantástico da literatura, mostrando a importância do hábito da leitura por meio da contação de histórias, poesias, recitais, brincadeiras, sorteio de livros, música e a imaginação aguçada através das atividades literárias. Todos que fazem a Praça do Sebo e trabalham com o livro, pensam igualmente em pluralizá-lo, além de divulgá-lo como um bom presente, certificam de que é uma fonte de conhecimento e prazer. Costumam deixar evidente aos clientes que acreditam que a Literatura Infantil e Juvenil é um instrumento lúdico e desafiador, que contribui para o desenvolvimento emocional e desperta na criança a curiosidade de compreender o contexto em que vive.

A boa repercussão, com o apoio da mídia, trouxe de volta a presença de alunos e pesquisadores, cumprindo, assim, um dos maiores objetivos do projeto: levar cada leitor até o seu livro, criando uma relação desde cedo, impulsionando a literatura e a cultural local. Após quase um ano de intensa movimentação em torno da Praça do Sebo, é criado o "Abril pro Livro", evento para comemorar o Dia Mundial do Livro e celebrar a importância da leitura junto com a história da Praça, além de sempre abordar um bate-papo sobre formação de leitores em tempos atuais, literatura pernambucana ou o processo de escrita. A ocasião, desde a primeira edição, ficou marcada pelo grande número de parcerias e amigos envolvidos em sua realização, resultando numa vitória conjunta para cidade e para educação, exaltando exatamente os interesses da população para aquele local. 
Dentre as parcerias podemos citar os bibliotecários da Rede de Bibliotecas pela Paz da Prefeitura do Recife, a Secretaria de Segurança Urbana do Recife, um grupo de alunos e professores do curso de Biblioteconomia da UFPE; alunos do curso de Design da Informação, da AESO, alunos do curso de Arquitetura da UFPE, alunos do curso de Turismo da Faculdade Joaquim Nabuco, a Editora Cartonera Pé de Letra, todos os sebistas da Praça do Sebo e alguns profissionais autônomos como as contadoras de história Roma Júlia, Flavioleta Diana e Karoline Maciel, os poetas Jimmy Marcone e Igor Westphalen, o cartunista Clodoaldo Turcato, e vários outros Coletivos e artistas independentes da RMR.

O projeto \#MovimentePraçaDoSebo, surgiu desse estudo sobre a "Ressignificação de Praças Públicas", transformou-se numa causa de apropriação e requalificação, com o intuito de mostrar o potencial cultural, turístico e artístico, a energia que vive no lugar desde os anos 1980, e impulsionar a evolução urbana da praça e de seu entorno. Preenchendo-a de eventos e atividades orientadas e, especialmente, criando a oportunidade de vivenciar experiências literárias em nossa cidade, incentivando a leitura e cultura do livro. Os livreiros da Praça passaram a ser convidados para feiras literárias, nas quais puderam participar e expor suas obras ao lado de editoras, em estandes dedicados à Praça do Sebo, e as vendas aumentaram, de acordo com depoimentos dos mesmos.

Com quase dois anos de projeto, foi realizado a segunda edição do "Abril pro Livro", que atingiu, nas redes sociais, um surpreendente número de 101 mil interessados no evento. A ideia de promover um espaço sociocultural para formação de leitores passou a ser vista cada vez mais como relevante, e viabilizar experiências leitoras significativas em meio a uma praça pública não era mais uma intenção tão distante. Nos anos de atuação e estudo, outros tantos eventos literários, infantis e culturais foram realizados, sempre utilizando do grande pátio para manifestações artísticas, enquanto a venda de livros acontecia normalmente. A Praça conseguiu ampliar as oportunidades de encontro com as múltiplas vozes e referências através da leitura, se tornando parâmetro em trocas 


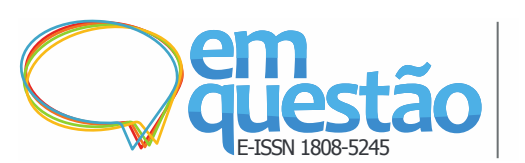

e atos literários, com intensa divulgação e apoio da mídia local (rádio, jornal e tv).

As propostas de mediação cultural, constantemente, têm sido apresentadas ao poder público, mas a Praça do Sebo ainda não obteve um retorno efetivo e positivo diante de tudo o que é almejado. Incontestavelmente, a Praça do Sebo avançou bastante, no que diz respeito à divulgação, mas ainda não se configura como a praça pública que vende livros novos e usados no Recife e possibilita inúmeras interações culturais que todos gostariam de ver mantida e funcionando. As ações realizadas ainda são poucas perante um calendário que pode ser preenchido. O espaço precisa de atenção das políticas públicas municipais para desenvolver seu potencial. A parceria com o Departamento de Ciência da Informação da Universidade Federal de Pernambuco tem rendido um esforço para transformar as experiências de ações já realizadas em um projeto de extensão, para que haja mais possibilidades de consolidar a mediação cultural de forma mais contínua.

Mobilizar é uma tarefa que exige sensibilização nas pessoas. Empreender socialmente é um ato de impacto que deve estar cada vez mais intrínseco ao profissional bibliotecário, que escolhe atuar no âmbito social ao utilizar-se da mediação de informação e cultura para despertar mudanças na vida de outras pessoas. A Praça do Sebo é um lugar único no Recife, que atende às mais inusitadas demandas dos leitores. Acredita-se na evolução e continuidade dessa mudança e na ressignificação espacial e cultural da Praça do Sebo para que ela se torne cada vez mais um ambiente dialógico. Entrar no fluxo do diálogo significa rejeitar a palavra monológica, que alicia o outro de modo imperioso e antepara o aparecimento da atitude de evento que ostenta o sentido das interações sociais. O dialogismo faz reverência ao constante diálogo, nem sempre regular e suave, vivente entre as dessemelhantes palavras que conformam a cultura. É ele o artifício que constitui a índole interdiscursiva da linguagem, da mediação cultural e dos objetos culturais, da abertura a alteridade para a constituição de identidades e de novos sentidos.

Para ressignificar um espaço, efetivamente, é necessário, antes de tudo, estar inserido o máximo naquele enredo, entendendo e vivenciando a rotina e 


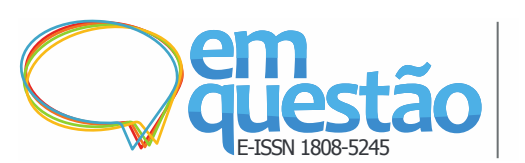

A ressignificação da praça pública e do sebo como lugares de mediação cultural Hélio Márcio Pajeú e Ana Carolina Correia Sobral

sua historicidade. Após a ideia do projeto concebida, apresentada e aceita pelos livreiros, e com a página no Facebook criada, foi possível escutar o que as pessoas que vivem do livro e para o livro tinham a dizer, foi possível, também, reconstituir a memória coletiva da praça pela história oral que foi relatada em forma de postagem, um pouco de cada sujeito que a constitui de algum modo.

\section{Considerações finais}

Primeiro ponto relevante deste trabalho, o qual consideramos que deva ser acatado como uma das maiores contribuições postas, é o exemplo de prática, atuação e campo profissional. No momento em que se iniciou essa labuta a partir da mediação cultural, tendo como cenário a Praça do Sebo, não se estava apenas afunilando anseios pessoais, mas tentando, de certa forma, ressignificar, também, o papel do bibliotecário em Pernambuco, ao se promover maneiras de assegurar a educação permanente, que pode ser vivida em tantos cantos, na rua, ao ar livre, na Praça.

A Biblioteconomia não deve pautar sua existência apenas nos aspectos técnicos do fazer das bibliotecas e centros de documentação, visto que, a técnica pura, por si só, não objetiva ou justifica nada, mas sim instrumentaliza e intermedia outro prisma: aquilo que se deseja, os processos de mediação em qualquer esfera que se tenha o homem e sua cultura interagindo. Percebe-se, então, que a técnica na biblioteconomia só é válida porque ajuda a alcançar e satisfazer objetivos informacionais, porque media também objetos culturais. Como disse Fonseca (2007, p. 50), “a missão do bibliotecário, que era quase exclusivamente bibliocêntrica, passa a ser também antropocêntrica; ou, antropobibliocêntrica: designação que evidencia ser o elemento humano ainda mais importante que o elemento documento", ao se transferir o foco da informação para o usuário.

Parece-nos estar ficando mais evidente, entre os estudantes de biblioteconomia, o desejo do protagonismo social e de se portarem não apenas como meros espectadores. A atualização constante da grade curricular, a preocupação em inserir o aluno em atividades extensionistas, traz com si novas 


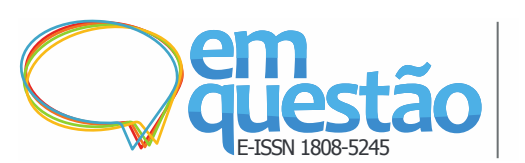

A ressignificação da praça pública e do sebo como lugares de mediação cultural Hélio Márcio Pajeú e Ana Carolina Correia Sobral

reflexões e proporciona um aumento de autoestima da profissão junto ao papel cumprido em sociedade, como uma profissão responsiva, isto é que responde as demandas sociais e tem um comprometimento com as mesmas. Essa consciência tem ficado mais clara e as novas possibilidades de atuação também. Esse fato mexe nas estruturas já consolidadas, mostra uma universidade amplificada, aberta e dialógica que impulsiona o engajamento social, a formação na prática, e desperta conhecimento da realidade social.

Nunca sabemos o que virá pelas páginas de um livro, só temos a certeza de que em muito nos acrescentará. Esse é o sentimento de Cátia Sales, livreira da Praça do Sebo, pelo qual ela acredita que todo livro tem seu dono, a gente procura o livro e o livro procura a gente, e não importa o tempo que demore na estante, um dia ele chega.

Entender esse leitor "que um dia chegará"; fazer com que esse público se aproxime; resgatar a expressividade do lugar, até então apático; foram desafios superados através da mediação cultural, comprovando que existem lugares na cidade do Recife espontaneamente incríveis, esperando apenas por uma ação reveladora de seus encantos. Pode-se dizer, sobre a Praça do Sebo, após estudar e vivenciar com afinco a sua historicidade, que ela possui dois grandes marcos em seus 35 anos de existência.

Na década de 80, em sua inauguração em 1981 e nos primeiros dez anos que se seguiram (nos quais, de fato, se viu cumprir os objetivos de "lazer e cultura" propostos), quando os sebistas que trabalhavam nas calçadas foram transferidos; e o pós projeto \#MovimentePraçaDoSebo, que desde sua chegada, em 2013, tem trazido mudanças e novas esperanças no processo dialógico de interação, vivência e mediação cultural nesse espaço. É perceptível que os efeitos das ações realizadas foram valorativamente considerados positivos para a divulgação do trabalho dos livreiros e para um despertar de olhar mais atento sobre o espaço e o interesse na temática. O estudo sobre sebos e a história do livro, sobre ações culturais e promoção da leitura - hoje visto como serviço vital para o bem-estar social; está longe de esgotar-se. Outros escritos e contínuas ações deverão ser elaboradas, a participação do Departamento de Ciência da 
Informação da UFPE nesta luta trará novos ares e a divulgação deste trabalho na Prefeitura da Cidade do Recife trará novos parceiros e crentes na causa.

Não há melhor forma de enxergar a imagem de uma cidade, ou conhecer de perto seu estilo de vida, do que uma ida ao mercado, a uma feira, a uma praça. É onde se revelam, espontaneamente e autenticamente, os hábitos e gostos hoje e de ontem, a relação dos habitantes com seus espaços públicos. São os lugares essenciais de nascedouro das ideologias que se materializarão discursivamente na superestrutura, segundo Bakhtin (2008). As livrarias alfarrabistas, bem como os alfarrábios, estão a preservar a memória registrada e resguardar a cultura. Defensores ávidos do livro, os sebistas trabalham conservando-o, difundindo informação, fomentando o conhecimento, estimulando e incentivando a leitura.

Dar voz à Praça do Sebo, através das redes sociais e eventos, conversar com alfarrabistas e frequentadores, nos faz despertar para um extenso conteúdo histórico referente ao espaço propriamente dito e ao caminho percorrido pelo livro (desde sua produção, circulação e recepção). Os sebos, dada à dimensão cultural, têm grande relevância para a vida cotidiana de uma cidade. Essa investigação ainda trilhará um longo percurso, junto aos tantos personagens que participaram do processo de pesquisa, desvendando o mundo dos alfarrábios no coração do Recife.

Estudar a ressignificação de uma praça pública, dentro do fazer-cultural do bibliotecário, se materializou como objeto de pesquisa, a partir da mediação cultural desenvolvida nesse espaço, podia-se formar um conjunto de agentes transformadores e não mais de meros expectadores que fariam parte da mudança. E o papel do mediador ali era interfacear, intermediar: o leitor com a praça, com a fanpage da praça; o livreiro com o leitor, com a praça, com as atividades; a população com as ações, com o centro da cidade, com o livro a baixo preço, com a leitura. O papel do mediador rodeado de ações funcionou como lugar de conexões, de consumo cultural e de produção de saberes e de sentidos. 


\section{Referências}

ABBAGNANO, N. Dicionário de filosofia. São Paulo: Martins Fontes, 1998.

ALBERTIM, M. Praça do Sebo. In: PORTAL VERMELHO. São Paulo: AssociaçãoVermelho, 2012.

ALMEIDA, M. C. B. A ação cultural do bibliotecário: grandeza de um papel e limitações da prática. Revista Brasileira de Biblioteconomia e

Documentação, São Paulo, v. 20, n. 14, p. 31-38, jan./dez. 1987.

AMORIM, A. C. Sebos e o acesso a memória escrita na cidade de Fortaleza/CE: um estudo preliminar. In: SIMPÓSIO NACIONAL DE HISTÓRIA, 27., 2013, Natal. Anais... Natal: Associação Nacional de História, 2013.

ANDRADE, T. B.; BOVO, M. C. A significação e a dinamicidade social dos espaços públicos urbanos: a história de duas praças e uma rua em Campo Mourão/PR. Geografia em atos, Presidente Prudente, v. 1, n. 11, 88-94, 2011.

ANTUNES, G. A. S. A organização da informação em sebos de Porto Alegre. 2010. Trabalho de conclusão de curso (Bacharelado em Biblioteconomia) - Faculdade de Biblioteconomia e Comunicação, Universidade Federal do Rio Grande do Sul, Porto Alegre, 2010.

BAKHTIN, M. A cultura popular na Idade Média e no Renascimento: o contexto de François Rabelais. Tradução Yara Frateschi. São Paulo: Hucitec, 2008 .

BAKHTIN, M. Para uma filosofia do ato responsável. São Carlos: Pedro \& João, 2010.

CABRAL, A. M. R. Ação cultural: possibilidades de atuação do bibliotecário. In: VIANNA, M. M.; CAMPELLO, B.; MOURA, V. H. V. Biblioteca escolar: espaço de ação pedagógica. Belo Horizonte: UFMG, 1999. p. 39-45.

CALDEIRA, J. M. A praça brasileira: trajetória de espaço urbano - origem e modernidade. 2007. Tese (Doutorado em História) - Instituto de Filosofia e Ciências Humanas, Universidade Estadual de Campinas, Campinas, 2007.

CAVAGLIERI, M.; STEINDEL, G. E. Um lugar para observar, conversar, ler, comprar - livros e outros suportes de informação e lazer: uma análise dos sebos da cidade de Florianópolis. Informação \& Sociedade: Estudos, João Pessoa, v. 19, n. 3, p. 55-64, set./dez. 2009.

COELHO NETO, J. T. O que é ação cultural. São Paulo: Brasiliense, 2001. (Coleção primeiros passos, 216).

COELHO NETO, J. T. Usos da cultura: políticas de ação cultural. Rio de Janeiro: Paz e Terra, 1989. (Educação e comunicação, v. 16). 
DE ANGELIS, B. L. Domingues et al. Praças: História, Usos e Funções.

Maringá: EDUEM - Ed. Universidade de Maringá. 2005. (Fundamentum, 15).

DELGADO, M. C. Cartografia sentimental de sebos e livros. Belo Horizonte: Autêntica, 1999.

ELLIOT, J. La investigación-accióneneducación. Tradução de Pablo Manzano. 3. ed. Madrid: Morata, 1997.

FARIAS, P. A. Entrevista concedida a Ana Carolina Sobral. Entrevistadora: Ana Carolina Sobral. Recife: [s.n.], 10 maio 2015.

FRANCE. Ministère de l'équipement et du logement, Plan urbain, Direction de l'architecture et de l'urbanisme. Délégation à la recherche et à l'innovation. Espaces Publics: groupe de travail. Paris: La Documentation Française, 1988.

FREIRE, P. Educação Como Prática da Liberdade. Rio de Janeiro: Paz e Terra, 1975.

FREITAS, L. Uma outra leitura para a Praça do Sebo. Jornal do Commercio, Recife, 16 fev. 2014.

JOSÉ FILHO, B. Ação cultural: atuação do bibliotecário como agente cultural na sociedade contemporânea. 2009. Trabalho de conclusão de curso (Bacharelado em Biblioteconomia) - Centro Universitário de Formiga, Formiga, 2009.

LIMA, M. Sebos uma atividade que vai do antigo ao contemporâneo. Revista Eletrônica do Grupo Educacional Uninter. Curitiba, n.52, agosto 2009.

LOUZADA, R. L. Uso e ocupação privativa de áreas públicas para fins comerciais. Itambé: [s.n.], 2011.

MAGNANI, J. G. De perto e de dentro: notas para uma etnografia urbana. Revista Brasileira de Ciências Sociais, São Paulo, v. 17, n. 49, p. 11-29, 2002.

MANSUR, André Lemos. Exaltação aos sebos. O Globo, Rio de Janeiro, 25 set. 2007. Blog Paralelos.

MENEZES, C. Degradação: Praça do Sebo sofre com falta de estrutura. Portal Imprensa, 2006.

MULLER, S. P. M. Biblioteca e sociedade: evolução da interpretação de função e papéis da biblioteca. Revista da Escola de Biblioteconomia da UFMG, Belo Horizonte, v. 13, n. 1, p. 7-54, mar. 1984.

NASCIMENTO, M. P. A Praça do Sebo e o mercado livreiro no Recife. In: CONGRESSO INTERNACIONAL DE LITERATURA NORDESTINA, 1., 
1988, Anais... Recife: Universidade Federal de Pernambuco/Editora Universitária, 1988. p. 28-32.

PERROTTI, E. PIERUCCINI, I. A mediação cultural como categoria autônoma. Informação \& Informação, Londrina, v. 19, n. 2, p. 01-22, out. 2014.

ROBBA, F.; MACEDO, S. S. Praças Brasileiras. São Paulo: EDUSP, 2003.

SARACEVIC, T. Ciência da informação: origem, evolução e relações.

Perspectivas em ciência da informação, Belo Horizonte, v. 1, n. 1, p. 41-62, jan./jun. 1996.

SILVA, C. S. C. et al. Ressignificação da experiência de Orientação Profissional. Revista Brasileira de Orientação Profissional, São Paulo, v. 9, n. 1, jun. 2008.

SOUSA, R. O.; OLIVEIRA, C. E. A praça como lugar da diversidade cultural. In: FORÚM DE EDUCAÇÃO E DIVERSIDADE, 4., 2010, Tangará da Serra. Anais... Tangará da Serra: UNEMAT, 2010.

WERSIG, G., NEVELING, U. The phenomena of interest to information science. Information Scientist, v.9, p. 127-140, 1975.

\title{
Resignifying the public square and the sebos as places of cultural mediation
}

\begin{abstract}
The paper presents part of an ethnomethodological research, that begun in July 2013, about the Praça do Sebo located in the city of Recife's downtown, which since 1981 has been housing sebos in 19 boxes, becoming a unique space in the city for the sale of old, new, rare and used books. It tried to understand the concept of public square and its importance for the configuration of citizenship, in order to establish a possibility of re-signification of the urban spaces from the cultural mediation. It historically situates the relation between booksellers and the space in the construction of collective memories and it approaches the problematic of the librarian as producer and mediator of culture. It presents the practices of the project \#MovimentePraçaDoSebo and some results achieved, reporting the experiences and cultural actions already carried out during its development.
\end{abstract}

Keywords: Cultural mediation. Reading. Public spaces. Public squares. Recife.

Recebido: 26/03/2018

Aceito: 28/06/2018

${ }^{1}$ Entrevista concedida a Ana Carolina Sobral, Recife, 10 maio de 2015. 